\title{
Dihydroergotamine affects spatial behavior and neurotransmission in the central nervous system of Wistar rats
}

\author{
Agnieszka Piechal ${ }^{1, A-F}{ }^{\oplus}$, Kamilla Blecharz-Klin ${ }^{1, B-C, E-F} \oplus$, Ilona Joniec-Maciejak ${ }^{1, B, E-F} \oplus$, \\ Justyna Pyrzanowska ${ }^{1, B-F} \oplus$, Kinga Krzysztoforska ${ }^{1, B, E-F}{ }^{1}$, Dagmara Mirowska-Guzel ${ }^{1, C, E-F} \oplus$, \\ Ewa Widy-Tyszkiewicz ${ }^{1, A-C, E-F} \oplus$ \\ ${ }^{1}$ Centre for Preclinical Research and Technology CePT, Medical University, Warsaw, Poland \\ A - Research concept and design, B - Collection and/or assembly of data, C - Data analysis and interpretation, \\ $D$ - Writing the article, E - Critical revision of the article, $F$ - Final approval of article
}

\begin{abstract}
Piechal A, Blecharz-Klin K, Joniec-Maciejak I, Pyrzanowska J, Krzysztoforska K, Mirowska-Guzel D, Widy-Tyszkiewicz E. Dihydroergotamine affects spatial behavior and neurotransmission in the central nervous system of Wistar rats. Ann Agric Environ Med. 2021; 28(3): 437-445. doi: $10.26444 / a a e m / 126020$
\end{abstract}

\begin{abstract}
Introduction. Dihydroergotamine (DHE) is a derivative of an ergot alkaloid used as an antimigraine medication. Nowadays, ergot alkaloids may still endanger the safety of humans and animals as food or medicine pollutants, but the outcomes of long-term DHE administration on the behaviour and neurotransmission remain undescribed.

Materials and method. Adult male Wistar Albino Glaxo rats pre-treated orally with DHE for six weeks were investigated to assess the relationship between concentration of neurotransmitters and behavioural response. The behavioural effects of the drug administered at doses of either $30 \mu \mathrm{g} / \mathrm{kg}$ b.w. (group DHE30, $\mathrm{n}=11$ ) or $100 \mu \mathrm{g} / \mathrm{kg}$ b.w. per day (group DHE100, $\mathrm{n}=10$ ) were evaluated in the Morris Water Maze. It is known that monoaminergic neurotransmitters (serotonin, noradrenaline and dopamine) in some brain structures (prefrontal cortex, hippocampus, striatum, cerebellum, spinal cord) play a role in the control of cognitive and motor functions. The concentration of neurotransmitters was determined by High Performance Liquid Chromatography (HPLC).

Results. Administration of DHE influenced neither the learning processes nor memory in rats. Nevertheless, an increased motor activity of the DHE-administered animals was observed in both the cued and non-cued behavioural tasks. In HPLC examination, changes in the concentration of monoaminergic neurotransmitters and their metabolites were noted in all tested structures, except for the hippocampus.

Conclusion. DHE is able to modulate noradrenergic, serotonergic and dopaminergic neurotransmission that may support the increase in locomotion.
\end{abstract}

\section{Key words}

behavior, memory, rats, brain, Neurotransmission, dihydroergotamine, ergot derivatives

\section{INTRODUCTION}

Dihydroergotamine (DHE) is a derivative of an ergot alkaloid - ergotamine. Excessive exposure to ergot compounds, traditionally due to the ingestion of the alkaloids produced by the Claviceps purpurea (fungus infecting rye and other cereals), could result in ergotism. Nowadays, ergot alkaloids still pose a threat to the safety of humans and animals, as food or medicine pollutants, e.g. dihydroergotamine content has been detected in marine biota of the Baltic Sea [1].

Dihydroergotamine is used today mainly in the treatment of migraine pain. In its structure DHE is similar to biogenic amines, such as noradrenaline, adrenaline, dopamine and serotonin. As commonly used triptans, DHE activates 5- $\mathrm{HT}_{1 \mathrm{~B}}$ and $5-\mathrm{HT}_{1 \mathrm{D}}$ receptors, also stimulating other serotonergic $\left(5-\mathrm{HT}_{1 \mathrm{~A}}, 5-\mathrm{HT}_{2 \mathrm{~A}}, 5-\mathrm{HT}_{1 \mathrm{~F}}, 5-\mathrm{HT}_{2 \mathrm{C}}, 5-\mathrm{HT}_{3}\right)$, dopaminergic $\left(\mathrm{D}_{1}, \mathrm{D}_{2}\right)$ and $\alpha$-adrenergic receptors [2-4]. The mechanism of analgesic action is associated with contraction of the cranial blood vessels that leads to decreased blood flow through the

Address for correspondence: Justyna Pyrzanowska, Medical University, Warsaw Centre for Preclinical Research and Technology CePT, Banacha 1b, 02-097 Warsaw, Poland

E-mail: justyna.pyrzanowska@wum.edu.pl

Received: 29.11.2019; accepted: 03.08.2020; first published: 20.10.2020 brain tissue, and commonly is attributed to the agonistic effect at $5-\mathrm{HT}_{1 \mathrm{D}}$ receptors [5]. It is also known that $\mathrm{DHE}$ blocks activation of the trigeminal nucleus caudalis, thus inhibiting the release of proinflammatory prostaglandins from the glia [6]. Moreover, it causes secondary inhibition of calcitonin gene-related peptide (CGRP), and decreases the expression of $\mathrm{P} 2 \mathrm{X} 3$ membrane receptors [7]. Current indications for DHE cover mainly acute migraine management. Although some new drugs, such as triptanes, were introduced to therapy, dihydroergotamine still occurs in recommendations [8-10]. There are also data supporting the use of DHE in menstrual migraine, migraine with central sensitization and cutaneous allodynia, medication-overuse headache, migraine recurrence, and migrainous state [11]. Although DHE administration according to EMA [12] needs consideration resulting from its potential toxicity (fibrosis), it is still a good alternative for patients with a migrainous state, migraine recurrence or chronic daily headaches that do not respond to classical therapy.

There are also some reports on the use of ergot alkaloids in memory disorders. The formerly occurring poisonings with ergot alkaloids of Claviceps purpurea, that could be manifested as mental impairment (mania or psychosis), indicated their impact on central nervous system activity. 
One of the ergotamine derivatives tested was nicergoline, a semisynthetic ergot derivative shown to have some beneficial effect on cognition and behaviour in various forms of dementia in terms of clinical global impression [13]. Also, Saletu et al. [14] assessed the impact of nicergoline administration on cognitive function disorders. On the basis of the overview, the authors demonstrated that the drug could be a safe therapeutic option for patients with memory disorders. Although in some reports the potential adverse effects of nicergoline are described, in particular the occurrence of hypertension and fibrosis, they do not seem to be a significant threat [15]. Despite the research, the influence of dihydroergotamine on cognition and behaviour remains unexplored.

It is known that monoaminergic neurotransmitters (serotonin, noradrenaline and dopamine) in some brain structures (prefrontal cortex, hippocampus, striatum, cerebellum, spinal cord) play a role in the control of cognitive and motor functions [16]. Although the mechanism of action of dihydroergotamine engages monoaminergic transmission, there is no available data about how DHE may affect the behaviour of rodents. Considering the lack of proper research, the authors of the current study decided to discover whether long-term administration of DHE is able to affect the behaviour of rats in a water maze.

DHE as an oral solution is absorbed from the gastrointestinal tract but its bioavailability is rather modest [17]. The efficacy of the drug seems to be independent of its blood plasma level due to prolonged diffusion from the receptor biophase. DHE can pass the blood-brain barrier - a certain amount was detected in cerebrospinal fluid [18]. Goadsby et al. [19] determined the distribution of ${ }^{3} \mathrm{H}$-dihydroergotamine in the central nervous system of cats. The highest drug binding density was observed in the mesencephalon, in particular in the area of the dorsal raphe nucleus and, to a lesser extent, in the area of the brain stem, spinal cord and grey matter of the cerebral cortex. As there are also clinical observations indicating the effectiveness of long-term, orally administered DHE in the prevention of migraine $[20,21]$, it is therefore possible that administration of DHE per os may affect the activity of the central nervous system. It is hypothesized that the drug given to 3-month-old rats could change the level of biogenic amines and their metabolites in the structures of CNS responsible for learning, memory and motor functions. Such knowledge could be important for patients with migraine attacks who often use DHE preparations, as well as elucidating the effects of environmental exposure to ergot alkaloids.

\section{MATERIALS AND METHOD}

Animals and dihydroergotamine treatment. 3-month old, male Wistar Albino Glaxo rats weighing 250-300 g $(n=31)$ were used in the study. The animals received orally a solution of DHE (Dihydroergotamine tartrate, Fluka). The rats were randomly assigned to experimental groups receiving DHE solution at a daily intake of $30 \mu \mathrm{g} / \mathrm{kg}$ b.w. (DHE30, $\mathrm{n}=11$ ) or $100 \mu \mathrm{g} / \mathrm{kg}$ b.w. (DHE100, $\mathrm{n}=10$ ) [22]. Control animals (Con, $\mathrm{n}=10$ ) received tap water ad libitum. To estimate precisely the concentration of administered solutions, the daily consumption of liquids during the study was carefully monitored and their volume evaluated each day. Continuous assessment allowed for an average daily intake of DHE at the dose of $30 \pm 1 \mu \mathrm{g} / \mathrm{kg}$ b.w. in DHE30 and $100 \pm 2 \mu \mathrm{g} / \mathrm{kg}$ b.w. in DHE100 group, respectively. The body weight was checked each week and allowed for adjustment of the dihydroergotamine dose. Animals were housed 2 per cage in a room with a $12 \mathrm{~h}$ dark-light cycle, constant temperature of $24-26^{\circ} \mathrm{C}$ and humidity at about $60 \%$ [23]. The rats received standard chow (Labofeed, Kcynia, Poland). After 6 weeks of the treatment the rats were tested in the water maze. The administration of DHE was continued during behavioural tests.

After receiving the approval of the Ethical Committee for Animal Experiments at the Medical University of Warsaw. all animal procedures were carried out according to Directive 2010/63EU of the European Parliament and of the Council of 22 September 2010 on the protection of animals used for scientific purposes,

Behavioural tests. To evaluate the effect of DHE on behavior, all rats were tested using the Morris water maze [24]. The rats were trained to find an underwater platform $(10 \mathrm{~cm} \mathrm{x} 10 \mathrm{~cm})$ in a circular white swimming pool (diameter $-150 \mathrm{~cm}$, depth $-50 \mathrm{~cm}$ ) filled with water at the temperarture of $23^{\circ} \mathrm{C}$. The experiment was performed in a testing room which contained many cues enabling spatial navigation. The swimming pool was divided into 4 quadrants - South-East (SE), South-West (SW), North-East (NE) and North-West (NW), according to the experimental procedure. A plexiglass platform which was not visible to the animal, located in the center of the SE quadrant, was placed $1 \mathrm{~cm}$ below the surface of the water. During acquisition (day 1-4, trial 1-16), the animals learned the location of the underwater platform while performing 4 training sessions in which in each repetition the starting position was changed. Each training session began by placing a rat in the pool and ended when the rat reached the platform. The time limit in the trial was $60 \mathrm{~s}$, and the animals which were unable to reach the goal were placed on the platform for $15 \mathrm{~s}$ by the experimenter. On the fifth day (probe trial, trial 17), when spatial memory was evaluated, the rats were allowed to swim for $60 \mathrm{~s}$ to search for the platform that had been removed before the test.

After 2 days, the experiment was resumed and the rats were given repeated training (day 8 , trials 18-21). On the next day (Day 9, trials 22-25), the platform was moved to the opposite quadrant (NW) and animals were trained to find the new location. On day 10 (reverse probe, trial 26), the platform was removed from the pool and the second probe test was conducted.

On the following day 11 (trial 27-30), the platform was placed $2 \mathrm{~cm}$ above water level and was visible to the rats. The location of the platform was sequentially changed in a pseudorandom manner between the SE, NE, NW and SW quadrants.

Data on animal navigation, escape latency, path and swimming speed were recorded by an image analyzing system (Chromotrack, San Diego Instruments, USA) and videotaping.

Biochemical procedures - Monoamines. The concentration of dopamine (DA), its metabolites 3,4-dihydroxyphenylacetic acid (DOPAC) and 3-methoxytyramine (3-MT); 5-hydroxytryptamine (5-HT); 5-hydroxyindolacetic acid (5-HIAA); noradrenaline (NA), 3-methoxy-4- 
hydroxyphenylglycol (MHPG) and homovanilic acid (HVA), were determined using the HPLC method according to the protocols described in detail in previously published articles [25]. 24 hours after the behavioural tests, the rats were decapitated, their brains removed, after which the hippocampus, prefrontal cortex, striatum, cerebellum, medulla oblongata and spinal cord were completely dissected to assess their role in the modulation of cognitive and locomotor processes [16]. The tissues were weighed, frozen and stored at $-80^{\circ} \mathrm{C}$ for further quantifying the neurotransmitters. Homogenates (in $0.1 \mathrm{~N}$ perchloric acid) were centrifuged $\left(13,000 \mathrm{x} \mathrm{g}, 15 \mathrm{~min} ., 4^{\circ} \mathrm{C}\right)$ and the filtered supernatant was injected into the HPLC with electrochemical detection (L-3500 A detector; Merck). Monoamines were separated on a C-18 column (Nucleosil, Macherey-Nagel, Germany) at the mobile phase flow rate of $0.8 \mathrm{ml} / \mathrm{min}$. with the electrochemical potential set at $+0.8 \mathrm{~V} v$ s. an $\mathrm{Ag} /$ $\mathrm{AgCl}$ reference electrode. Neurotransmitters content was calculated as ng/g of fresh tissue by comparison with standard solutions of a known concentration, and analyzed by the computerized data acquisition system Clarity (DataApex, Czech Republic). All standards were purchased from SigmaAldrich (St. Louis, USA).

Statistical analysis. Statistical analysis was carried out using Statistica v.10 software (Statsoft, PL). The data were checked for its distribution using Shapiro-Wilk and Kolmogorov-Smirnov tests. Repeated measures analysis of variance ANOVA was used for behavioural analysis in the phase of learning and in the visible platform examination. Group differences in other water maze procedures and in biochemical analysis were assessed by one-way ANOVA. Significant behavioural and biochemical effects of DHE were indicated by post-hoc analyses (Newman-Keuls, NK) to determine specific differences. Cohen's d was used to calculate effect size categories $(>0.2-$ small, $>0.5$ - medium, and $>0.8$ - large effect size) [26]. All values were expressed as mean \pm SE with $\mathrm{p}<0.05$ considered statistically significant.

\section{RESULTS}

Behavioural results - Days 1-4: Learning. During the first 4 days of the experiment, the repeated measures ANOVA showed statistically significant differences in the speed of swimming of the tested rats $\left(\mathrm{F}_{(2,28)}=4.61 ; \mathrm{p}=0.018\right)$. Groups of DHE-treated animals (DHE30 $=0.29 \pm 0.0 \mathrm{~m} / \mathrm{s}$; DHE100 $=0.28 \pm 0.01 \mathrm{~m} / \mathrm{s}$ ) were swimming faster than the rats from the control group (Con $=0.26 \pm 0.01 \mathrm{~m} / \mathrm{s}$ ), but statistically significant differences were noted between DHE30 group and Con group ( $p=0.015$; Newman Keuls, NK) (Fig. 1A).

There were no significant differences both in escape latency $\left(\mathrm{F}_{(2,28)}=0.58 ; \mathrm{p}=0.58\right)$ and path length $\left(\mathrm{F}_{(2,28)}=0.40\right.$; $\mathrm{p}=0.67)$ towards the hidden platform. Both groups of rats had similar results in terms of time (Con $=20.86 \pm 1.46 \mathrm{~s}$, DHE30 $=19.75 \pm 1.35 \mathrm{~s}, \quad$ DHE $100=21.76 \pm 1.45 \mathrm{~s})$ and path length $($ Con $=5.24 \pm 0.37 \mathrm{~m} ; \mathrm{DHE} 30=5.35 \pm 0.35 \mathrm{~m}$; $\mathrm{DHE} 100=5.66 \pm 0.37 \mathrm{~m}$ ) required to find the platform.

Day 5 - First Memory Probe Trial. On day 5 of the experiment, analysis of variance did not show a significant difference in the crossing over from the previous position of the platform in SE quadrant $\left(\mathrm{F}_{(2,28)}=0.22 ; \mathrm{p}=0.81\right)(\mathrm{Con}=5.4 \pm 1.15$,
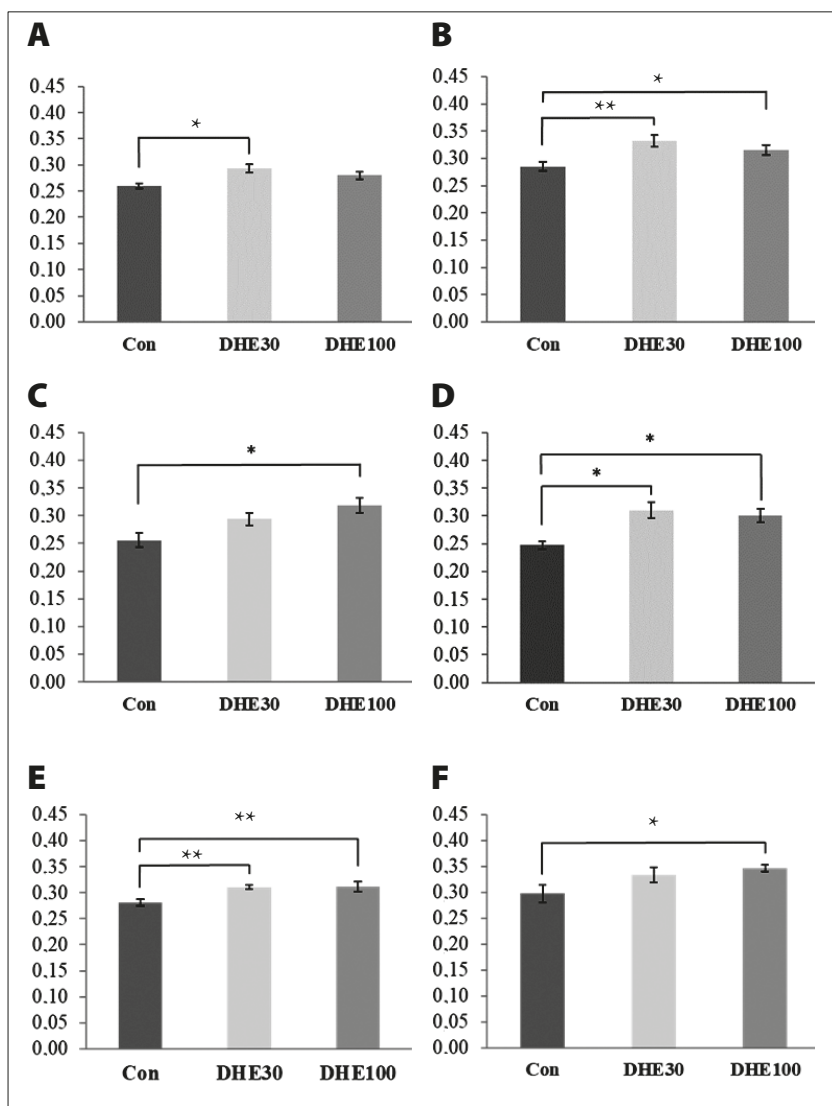

Figure 1. Effect of long-term oral administration of dihydroergotamine to adult Wistar male rats on swimming speed $(\mathrm{m} / \mathrm{s})$ during the learning phase (days $1-4$; A), both memory probe trials (days 5 and $10 ; B$ and E), repeated training (day $8 ; C$ ), reversal training (day $9 ; \mathrm{D}$ ) and visible platform examination $(\mathrm{F})$.

* DHE30, DHE100 vs Con ( $p<0.05 ; \mathrm{NK})$;

** DHE30, DHE100 vs Con $(p<0.01 ; N K)$.

DHE30 $=5.27 \pm 1.25$, DHE100 $=4.4 \pm 1.05$ ) (Fig. 2A). There were also no statistically significant differences in the time spent in the SE quadrant $\left(\mathrm{F}_{(2,28)}=0.09 ; \mathrm{p}=0.92(\mathrm{Con}=23.92 \pm 2.76 \mathrm{~s}\right.$; DHE30 $=25.25 \pm 2.65 \mathrm{~s} ;$ DHE100 $=24.05 \pm 2.03 \mathrm{~s}$ ) (Fig. 2B), but not in the swimming speed $\left(\mathrm{F}_{(2,28)}=6.34 ; \mathrm{p}=0.005\right)$. During the probe trial, the treated groups of rats were swimming faster in comparison to the control group $(\mathrm{Con}=0.28 \pm 0.01 \mathrm{~m} / \mathrm{s}$, $\mathrm{DHE} 30=0.33 \pm 0.01 \mathrm{~m} / \mathrm{s}, \mathrm{DHE} 100=0.31 \pm 0.01 \mathrm{~m} / \mathrm{s})($ Fig. $1 \mathrm{~B})$.

Day 8 - Repeated Training. On day 8, after a 2-day break, the hidden platform was placed again in the SE quadrant. After 4 trials, ANOVA indicated differences in the swimming speed in the groups of studied animals $\left(\mathrm{F}_{(2,28)}=4.43 ; \mathrm{p}=0.021\right)$. The control group was the slowest (Con $=0.26 \pm 0.01 \mathrm{~m} / \mathrm{s}$ ) compared to those treated with DHE (DHE30 $=0.29 \pm 0.01 \mathrm{~m} / \mathrm{s}$;

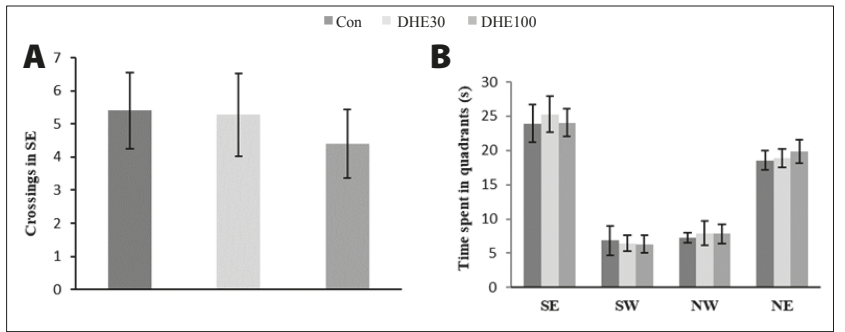

Figure 2. Effect of long-term oral administration of dihydroergotamine to adult Wistar male rats on crossings number (mean \pm SE) (A) and time spent in quadrants (s) (B) during first memory probe trial (day 5) 


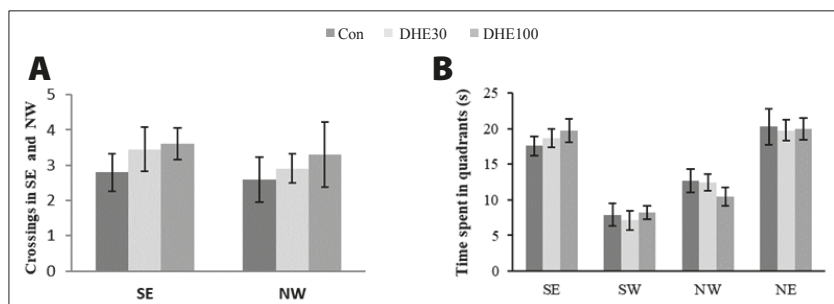

Figure 3. Effect of long-term oral administration of dihydroergotamine to adult Wistar male rats on crossings number (mean \pm SE) (A) and time spent in quadrants (s) (B) during second memory probe trial (day 10)

DHE100 $=0.32 \pm 0.01 \mathrm{~m} / \mathrm{s}$ ) (Fig. 1C). No statistically significant differences were noted either in escape latency $\left(\mathrm{F}_{(2,28)}=1.08\right.$; $\mathrm{p}=0.35)$ or in the path length $\left(\mathrm{F}_{(2,28)}=1.03 ; \mathrm{p}=0.37\right)$ to the platform. A small effect in size was observed for latency in the DHE100 group (Cohen's $\mathrm{d}=0.3$ ) with reference to Con.

Day 9 - Reversal Training. On day 9, the platform was placed in a new position in the NW quadrant. Significant differences were still noted, but only in the swimming speed $\left(\mathrm{F}_{(2,28)}=3.86 ; \mathrm{p}=0.03\right)$. Post hoc analysis showed that this was statistically increased in rats that were given both doses of DHE, compared to the control group (DHE30 vs. Con, $\mathrm{p}=0.039$; NK; DHE100 vs. Con, $\mathrm{p}=0.037$ ) (Fig. 1D). ANOVA did not show differences in escape latency $\left(\mathrm{F}_{(2,28)}=2.09\right.$; $\mathrm{p}=0.14)$ or path length $\left(\mathrm{F}_{(2,28)}=0.5 ; \mathrm{p}=0.61\right)$ required to find the new position of the platform. Cohen's d values showed small size effect for latency in DHE30 $(\mathrm{d}=0.38)$ and DHE100 $(\mathrm{d}=0.21)$ with reference to Con.

Day 10 - Second Memory Probe Trial. On day 10 of the experiment, the number of crossings the rats swam over the previous position of the platform in SE quadrant, as well as over the new one in NW quadrant, was registered. There were no statistically significant differences in that number, either over the old position $\left(\mathrm{F}_{(2,28)}=0.59 ; \mathrm{p}=0.56\right.$; Con $=2.8 \pm 0.53$; DHE30 $=3.45 \pm 0.62$; DHE100 $=3.6 \pm 0.45)$ or new position $\left(\mathrm{F}_{(2,28)}=0.26 ; \mathrm{p}=0.77 ; \mathrm{Con}=2.6 \pm 0.63 ; \mathrm{DHE} 30=2.9 \pm 0.41\right.$; DHE100 $=3.3 \pm 0.91$ ) of the platform (Fig. 3A). The number of crossings over the old platform position (SE) was the smallest in the control rats, and Cohen's d value showed small effect size for the DHE30 group $(\mathrm{d}=0.18)$, as well as medium effect size for DHE100 ( $d=0.54)$, compared to controls. Also, the number of crossings over to the new platform position (NW) was the smallest in the Con, and Cohen's d value showed small effect size for the DHE100 $(d=0.29)$ group. Moreover, there were no differences in time spent in the SE $\left(\mathrm{F}_{(2,28)}=0.56 ; \mathrm{p}=0.58\right)$ and $\mathrm{NW}\left(\mathrm{F}_{(2,28)}=0.81\right.$; $\mathrm{p}=0.45)$ quadrants (Fig. $3 \mathrm{~B})$. Swimming speed of the rats differed significantly $\left(\mathrm{F}_{(2,28)}=6.64 ; \mathrm{p}=0.004\right)$. Both groups of treated rats were swam much faster in comparison to the control group $($ Con $=0.28 \pm 0.01 \mathrm{~m} / \mathrm{s}$, DHE30 $=0.31 \pm 0.01 \mathrm{~m} / \mathrm{s}$, DHE100 $=0.31 \pm 0.01 \mathrm{~m} / \mathrm{s})(\mathrm{DHE} 30$ vs. Con, $\mathrm{p}=0.004, \mathrm{NK}$; DHE100 vs. Con, $\mathrm{p}=0.0087, \mathrm{NK}$ ) (Fig. 1E).

Day 11 - Visible Platform Test. On day 11, the visible platform was placed above the water level in the 4 quadrants of the pool. The swimming speed of the animals varied significantly $\left(\mathrm{F}_{(2,28)}=3.83 ; \mathrm{p}=0.033\right)$. The control group was the slowest when compared to the DHE100 group (Con $=0.30 \pm 0.02 \mathrm{~m} / \mathrm{s}$, DHE30 $=0.33 \pm 0.01 \mathrm{~m} / \mathrm{s}$, DHE100 $=0.35 \pm 0.01 \mathrm{~m} / \mathrm{s} ; \mathrm{p}=0.03$; $\mathrm{NK})$ (Fig. 1F). Escape latency $\left(\mathrm{F}_{(2,28)}=1.55 ; \mathrm{p}=0.23\right)$ and path

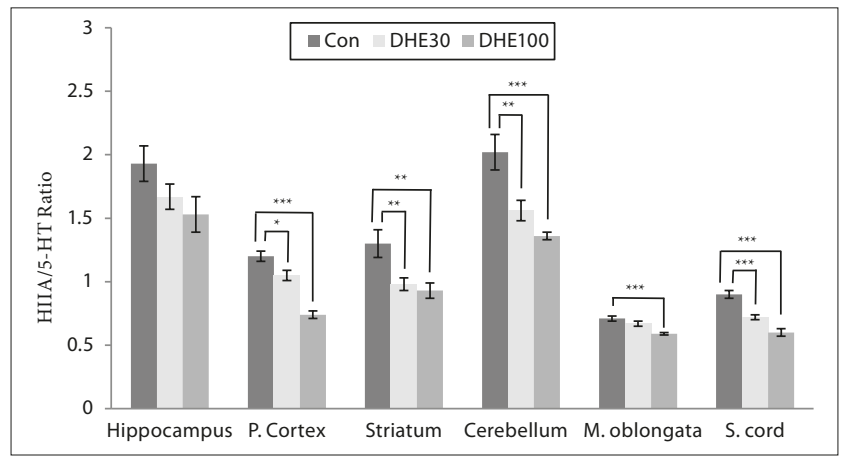

Figure 4. Effect of long-term oral administration of dihydroergotamine to adult Wistar male rats on 5-hydroxytryptamine turnover in selected brain regions (P. Cortex-Prefrontal cortex, M. oblongata - Medulla oblongata, S. cord - Spinal cord)

* DIH3, DIH10 vs Con $(p<0.05 ; \mathrm{NK})$;

** DIH3, DIH10 vs Con $(p<0.01 ; N K)$

*** DIH3, DIH10 vs Con $(p<0.001 ; N K)$

length $\left(\mathrm{F}_{(2,28)}=0.25 ; \mathrm{p}=0.78\right)$ to find the platform were similar in all groups.

Biochemical results - monoamines concentration in selected brain regions. The concentration of monoamines, their metabolites, as well as metabolite turnover calculated as the HVA/DA, DOPAC/DA, 5-HIAA/5-HT, MHPG/NA and $3 \mathrm{MT} / \mathrm{DA}$ ratios in chosen structures of the brain, are presented in Tables 1 and 2 .

Noradrenaline and metabolites. ANOVA analysis demonstrated significant differences between the control group and the DHE-administered groups of rats in noradrenaline content, both in the prefrontal cortex - PFC $\left(\mathrm{F}_{(2,28)}=12.29 ; \mathrm{p}=0.00015\right)$ and spinal cord $\left(\mathrm{F}_{(2,28)}=11.54\right.$; $\mathrm{p}=0.00022)$. Post hoc analysis showed increased levels of NA in the PFC (DHE100 vs. Con, $\mathrm{p}=0.00033$; DHE100 vs. DHE30, $\mathrm{p}=0.00057, \mathrm{NK})$ and spinal cord (DHE100 vs. Con, $\mathrm{p}=0.00033$; DHE100 vs. DHE30, $\mathrm{p}=0.0013)$. There were no significant differences in the concentrations of noradrenaline in the hippocampus $\left(\mathrm{F}_{(2,28)}=0.93 ; \mathrm{p}=0.41\right)$, striatum $\left(\mathrm{F}_{(2,28)}=0.23\right.$; $\mathrm{p}=0.8)$, cerebellum $\left(\mathrm{F}_{(2,28)}=2.04 ; \mathrm{p}=0.15\right)$ or medulla oblongata $\left(\mathrm{F}_{(2,28)}=1.14 ; \mathrm{p}=0.34\right)$.

MHPG concentration in the striatum $\left(\mathrm{F}_{(2,28)}=25.40\right.$; $\mathrm{p}=0.00000051)$, cerebellum $\left(\mathrm{F}_{(2,28)}=5.95 ; \mathrm{p}=0.007\right)$ and spinal cord $\left(\mathrm{F}_{(2,28)}=4.12, \mathrm{p}=0.027\right)$ was significantly different in the studied groups. In the striatum, the highest level of MHPG was noted in the group that was given the lowest dose of DHE, compared to the other groups. Similarly, in the cerebellum in the DHE100 group there was the lowest concentration of MHPG, which was statistically different from the control group and the DHE30 group. The highest concentration of MHPG was noted in the spinal cord of the DHE100 group. There were no significant differences in the concentration of MHPG in the hippocampus $\left(\mathrm{F}_{(2,28)}=0.07\right.$ : $\mathrm{p}=0.94)$, prefrontal cortex $\left(\mathrm{F}_{(2,28)}=0.75 ; \mathrm{p}=0.48\right)$ and medulla oblongata $\left(\mathrm{F}_{(2,28)}=1.78, \mathrm{p}=0.19\right)$.

The noradrenaline metabolite turnover (MHPG/NA) showed differences in the cerebellum $\left(\mathrm{F}_{(2,28)}=6.11 ; \mathrm{p}=0.006\right)$ but not in the other regions of the brain (hippocampus: $\mathrm{F}_{(2,28)}=0.12, \mathrm{p}=0.88$; PFC: $\mathrm{F}_{(2,28)}=0.33, \mathrm{p}=0.72$; striatum: $\mathrm{F}_{(2,28)}=2.78, \mathrm{p}=0.079$; medulla oblongata: $\mathrm{F}_{(2,28)}=1.71, \mathrm{p}=0.2$; spinal cord $\left.\mathrm{F}_{(2,28)}=1.23, \mathrm{p}=0.31\right)$. 
Table 1. Effect of long-term oral administration of dihydroergotamine on monoamine and metabolite levels (mean \pm SE) in selected brain regions in adult male rats (Con, $\mathrm{n}=10$; DHE30, $\mathrm{n}=11$; DHE100, $\mathrm{n}=10$ )

\begin{tabular}{|c|c|c|c|c|c|c|c|}
\hline \multirow{2}{*}{$\begin{array}{l}\text { Monoamine and } \\
\text { metabolite concentrations } \\
\text { (ng/g } \pm \text { SE) }\end{array}$} & \multirow{2}{*}{ Group } & \multicolumn{6}{|c|}{ Brain regions } \\
\hline & & Hippocampus & Prefrontal cortex & Striatum & Cerebellum & Medulla oblongata & Spinal cord \\
\hline & CON & $659.24 \pm 72.49$ & $454.38 \pm 12.01$ & $301.18 \pm 36.36$ & $357.33 \pm 10.63$ & $835.23 \pm 14.48$ & $282.19 \pm 16.47$ \\
\hline NA & DHE30 & $712.32 \pm 42.86$ & $466.41 \pm 10.16$ & $260.27 \pm 46.13$ & $385.51 \pm 9.21$ & $869.29 \pm 20.09$ & $302.45 \pm 13.78$ \\
\hline & DHE100 & $763.85 \pm 40.25$ & $539.23 \pm 16.37^{* * * \# \# \#}$ & $281.69 \pm 45.23$ & $370.83 \pm 10.09$ & $837.89 \pm 18.51$ & $374.61 \pm 11.66^{* * * \# \#}$ \\
\hline \multirow[b]{2}{*}{ MHPG } & CON & $1.78 \pm 0.64$ & $10.13 \pm 1.30$ & $19.15 \pm 1.31$ & $12.16 \pm 1.15$ & $10.72 \pm 1.03$ & $1.83 \pm 0.27$ \\
\hline & DHE30 & $1.65 \pm 0.54$ & $12.47 \pm 1.76$ & $41.05 \pm 2.99^{* * *}$ & $11.54 \pm 0.60$ & $10.52 \pm 0.69$ & $2.22 \pm 0.23$ \\
\hline \multirow{3}{*}{ DA } & CON & $80.42 \pm 46.81$ & $47.71 \pm 4.15$ & $3041.56 \pm 736.93$ & $6.01 \pm 0.89$ & $51.01 \pm 0.65$ & $26.71 \pm 1.83$ \\
\hline & DHE30 & $22.60 \pm 6.87$ & $42.42 \pm 23.02$ & $5412.12 \pm 10.36$ & $6.99 \pm 0.40$ & $55.97 \pm 1.35^{* *}$ & $29.30 \pm 1.86$ \\
\hline & DHE100 & $15.57 \pm 1.23$ & $40.885 \pm 2.24$ & $7358.40 \pm 563.37^{* *}$ & $6.75 \pm 0.52$ & $52.94 \pm 0.87^{\#}$ & $33.57 \pm 1.41^{*}$ \\
\hline \multirow{3}{*}{ DOPAC } & CON & $52.91 \pm 20.46$ & $32.76 \pm 2.36$ & $1041.91 \pm 256.28$ & $9.49 \pm 0.72$ & $33.48 \pm 1.34$ & $13.59 \pm 1.01$ \\
\hline & DHE30 & $31.77 \pm 5.59$ & $30.62 \pm 2.58$ & $1146.42 \pm 244.77$ & $11.48 \pm 0.85$ & $38.49 \pm 2.23^{*}$ & $12.71 \pm 1.08$ \\
\hline & DIH100 & $24.95 \pm 1.59$ & $27.65 \pm 2.08$ & $768.69 \pm 159.14$ & $9.30 \pm 0.65$ & $31.38 \pm 0.74^{\#}$ & $13.34 \pm 0.94$ \\
\hline \multirow{2}{*}{ HVA } & Con & $14.21 \pm 6.92$ & $14.35 \pm 1.58$ & $4.26 \pm 0.61$ & $4.71 \pm 0.31$ & $15.86 \pm 0.73$ & $4.26 \pm 0.61$ \\
\hline & DIH100 & $4.35 \pm 1.04$ & $10.67 \pm 1.58$ & $5.64 \pm 0.521$ & $3.66 \pm 0.21^{* \# \# \#}$ & $13.43 \pm 0.41^{* \# \#}$ & $5.64 \pm 0.52$ \\
\hline \multirow{3}{*}{$3 \mathrm{MT}$} & CON & & & $144.44 \pm 38.97$ & & & \\
\hline & DHE30 & $n / d$ & $\mathrm{n} / \mathrm{d}$ & $207.71 \pm 41.69$ & $n / d$ & $n / d$ & $\mathrm{n} / \mathrm{d}$ \\
\hline & DIH100 & & & $189.43 \pm 40.22$ & & & \\
\hline \multirow{3}{*}{ 5-HT } & CON & $370.97 \pm 83.43$ & $429.84 \pm 20.06$ & $324.63 \pm 26.93$ & $55.78 \pm 7.44$ & $646.23 \pm 12.07$ & $271.85 \pm 16.55$ \\
\hline & DHE30 & $367.19 \pm 30.12$ & $451.11 \pm 21.92$ & $432.17 \pm 17.96^{*}$ & $68.39 \pm 3.55$ & $675.82 \pm 10.93$ & $296.83 \pm 13.42$ \\
\hline & DHE100 & $361.22 \pm 42.18$ & $518.13 \pm 31.27^{*}$ & $420.97 \pm 33.99^{*}$ & $67.10 \pm 3.95$ & $686.03 \pm 12.04$ & 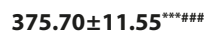 \\
\hline \multirow{3}{*}{ 5-HIAA } & CON & $659.00 \pm 118.62$ & $509.01 \pm 18.66$ & $405.30 \pm 25.14$ & $105.54 \pm 6.51$ & $456.94 \pm 6.87$ & $241.63 \pm 13.69$ \\
\hline & DHE30 & $590.22 \pm 29.22$ & $470.46 \pm 23.02$ & $422.73 \pm 25.35$ & $104.56 \pm 4.15$ & $453.51 \pm 14.02$ & $212.37 \pm 10.77$ \\
\hline & DHE100 & $508.77 \pm 19.62$ & $379.83 \pm 21.54^{* * * \# \#}$ & $375.73 \pm 18.54$ & $90.70 \pm 3.82$ & $405.32 \pm 10.54^{* * \# \#}$ & $221.86 \pm 8.10$ \\
\hline
\end{tabular}

Statistically significant differences $(\mathrm{p}<0.05)$ are presented in a bold font

$\mathrm{n} / \mathrm{d}$ - not detectable, NK - Newman-Keuls

* DHE30, DHE100 vs CON, $\mathrm{p}<0.05$ (NK)

*** DHE30, DHE100 vs CON, $p<0.001$ (NK) \#\# DHE30 vs DHE100, $p<0.001$ (NK)

Table 2. Effect of long-term oral administration of dihydroergotamine on metabolite turnover in selected brain regions in adult male rats (Con, $\mathrm{n}=10 ;$ DHE30, $\mathrm{n}=11$; DHE100, $\mathrm{n}=10$ )

\begin{tabular}{|c|c|c|c|c|c|c|c|}
\hline \multirow{2}{*}{$\begin{array}{l}\text { Metabolite } \\
\text { turnover }\end{array}$} & \multirow{2}{*}{ Group } & \multicolumn{6}{|c|}{ Brain regions } \\
\hline & & Hippocampus & Prefrontal cortex & Striatum & Cerebellum & Medulla oblongata & Spinal cord \\
\hline \multirow{3}{*}{ HVA/DA } & CON & $0.29 \pm 0.03$ & $0.31 \pm 0.03$ & $0.14 \pm 0.04$ & $0.85 \pm 0.07$ & $0.31 \pm 0.01$ & $0.16 \pm 0.02$ \\
\hline & DHE30 & $0.32 \pm 0.06$ & $0.35 \pm 0.06$ & $0.13 \pm 0.05$ & $0.82 \pm 0.07$ & $0.28 \pm 0.01$ & $0.14 \pm 0.01$ \\
\hline & DHE100 & $0.29 \pm 0.07$ & $0.26 \pm 0.04$ & $0.06 \pm 0.01$ & $0.56 \pm 0.03^{* * \# \#}$ & $0.25 \pm 0.01^{* *}$ & $0.17 \pm 0.01$ \\
\hline \multirow{3}{*}{ DOPAC/DA } & CON & $1.35 \pm 0.17$ & $0.71 \pm 0.04$ & $0.44 \pm 0.16$ & $1.68 \pm 0.11$ & $0.66 \pm 0.03$ & $0.51 \pm 0.03$ \\
\hline & DHE30 & $1.7 \pm 0.15$ & $0.74 \pm 0.04$ & $0.26 \pm 0.07$ & $1.65 \pm 0.10$ & $0.69 \pm 0.04$ & $0.44 \pm 0.02^{*}$ \\
\hline & DHE100 & $1.66 \pm 0.13$ & $0.68 \pm 0.04$ & $0.10 \pm 0.02$ & $1.40 \pm 0.07$ & $0.59 \pm 0.01$ & $0.39 \pm 0.02^{* *}$ \\
\hline \multirow{3}{*}{$\mathrm{HIIA} / 5-\mathrm{HT}$} & CON & $1.93 \pm 0.14$ & $1.20 \pm 0.04$ & $1.30 \pm 0.11$ & $2.02 \pm 0.14$ & $0.71 \pm 0.02$ & $0.90 \pm 0.03$ \\
\hline & DHE30 & $1.67 \pm 0.10$ & $1.05 \pm 0.04^{*}$ & $0.98 \pm 0.05^{* *}$ & $1.56 \pm 0.08^{* *}$ & $0.67 \pm 0.02$ & $0.72 \pm 0.02^{* * *}$ \\
\hline & DHE100 & $1.53 \pm 0.14$ & $0.74 \pm 0.03^{* * * \# \# \#}$ & $0.93 \pm 0.06^{* *}$ & $1.36 \pm 0.03^{* * * *}$ & $0.59 \pm 0.01$ & $0.60 \pm 0.03^{* * * \# \#}$ \\
\hline \multirow{3}{*}{ MHPG/NA } & CON & $0.002 \pm 0.001$ & $0.02 \pm 0.003$ & $0.09 \pm 0.03$ & $0.03 \pm 0.003$ & $0.01 \pm 0.001$ & $0.01 \pm 0.001$ \\
\hline & DHE30 & $0.003 \pm 0.001$ & $0.03 \pm 0.004$ & $0.27 \pm 0.09$ & $0.03 \pm 0.001$ & $0.01 \pm 0.001$ & $0.01 \pm 0.001$ \\
\hline & DHE100 & $0.002 \pm 0.001$ & $0.02 \pm 0.004$ & $0.12 \pm 0.03$ & $0.02 \pm 0.002^{* * \#}$ & $0.01 \pm 0.001$ & $0.01 \pm 0.001$ \\
\hline \multirow{2}{*}{ 3MT/DA } & CON & & & $0.06 \pm 0.02$ & & & \\
\hline & DHE100 & & & $0.03 \pm 0.004$ & & & \\
\hline
\end{tabular}

Statistically significant differences $(p<0.05)$ are presented in a bold font.

$\mathrm{n} / \mathrm{d}$ - not detectable, NK - Newman-Keuls

* DHE30, DHE100 vs CON, $p<0.05$ (NK)

** DHE30, DHE100 vs CON, $p<0.01$ (NK)

*** DHE30, DHE100 vs CON, $p<0.001$ (NK)

\# DHE30 vs DHE100, p $<0.05$ (NK)

\# DHE30 vs DHE100, $p<0.01$ (NK)

\#\#\# DHE30 vs DHE100, p<0.001 (NK)
Dopamine and metabolites. Significant differences in DA levels were noted in the striatum of the studied groups of rats $\left(\mathrm{F}_{(2,28)}=6.69, \mathrm{p}=0.004\right)$. Post hoc analysis showed the highest values of DA in the DHE100 group, which was significantly different from the control group. No differences were noted in the concentrations of striatal DOPAC $\left(\mathrm{F}_{(2,28)}=0.74 ; \mathrm{p}=0.48\right)$,
$\operatorname{HVA}\left(\mathrm{F}_{(2,28)}=3.00 ; \mathrm{p}=0.07\right)$ and $3-\mathrm{MT}\left(\mathrm{F}_{(2,28)}=0.65 ; \mathrm{p}=0.53\right)$, nor in the HVA/DA $\left(\mathrm{F}_{(2,28)}=1.27 ; \mathrm{p}=0.3\right)$, DOPAC/DA $\left(\mathrm{F}_{(2,28)}=2.82\right.$; $\mathrm{p}=0.08)$ ratio values.

In the cerebellum, visible differences were noted in the levels of HVA $\left(\mathrm{F}_{(2,28)}=9.99, \mathrm{p}=0.00053\right)$ and HVA/DA ratio $\left(\mathrm{F}_{(2,28)}=7.51, \mathrm{p}=0.002\right)$. Post hoc analysis showed the lowest 
concentration of HVA and HVA/DA ratio in the cerebellum of the rats from the DHE100 group; the results were significantly different from the other groups. No significant differences were noted in the cerebellum in the level of DA $\left(\mathrm{F}_{(2,28)}=0.66\right.$, $\mathrm{p}=0.53)$, DOPAC $\left(\mathrm{F}_{(2,28)}=2.64, \mathrm{p}=0.09\right)$ and DOPAC/DA ratio $\left(\mathrm{F}_{(2,28)}=2.5, \mathrm{p}=0.1\right)$.

In the medulla oblongata, there were significant differences in the concentrations of DA $\left(\mathrm{F}_{(2,28)}=5.99 ; \mathrm{p}=0.0067\right)$, DOPAC $\left(\mathrm{F}_{(2,28)}=5.21 ; \mathrm{p}=0.011\right), \mathrm{HVA}\left(\mathrm{F}_{(2,28)}=5.52 ; \mathrm{p}=0.0095\right)$, and HVA/ $\mathrm{DA}$ ratio $\left(\mathrm{F}_{(2,28)}=7.28 ; \mathrm{p}=0.0028\right)$ between the studied groups of rats. The concentration of dopamine and DOPAC was the highest in the group that was given a lower dose of DHE, and was statistically significant in comparison to other groups of animals (DA: DHE30 vs. Con, $\mathrm{p}=0.006$, NK; DHE30 vs. DHE100; $p=0.047, \mathrm{NK})$. On the other hand, the HVA/DA ratio in group DHE100 was the lowest and was different compared to the control group $(p=0.002, N K)$. ANOVA analysis did not demonstrate significant differences between the studied groups with regard to the DOPAC/DA ratio in the medulla oblongata $\left(\mathrm{F}_{(2,2)}=3.03 ; \mathrm{p}=0.0064\right)$, although a tendency was noted for this ratio to have lower values in the DHE100 group compared to other groups.

In the spinal cord, significant differences were noted in the level of DA $\left(\mathrm{F}_{(2,28)}=3.9, \mathrm{p}=0.032\right)$ and DOPAC/DA ratio $\left(\mathrm{F}_{(2,28)}=6.73, \mathrm{p}=0.004\right)$. DA content was higher in the groups that were given DHE, and the difference was noted between DHE100 group and Con group $(p=0.023$; NK). There were no differences in the spinal cord in the levels of DOPAC $\left(\mathrm{F}_{(2,28)}=0.2 ; \mathrm{p}=0.82\right)$, HVA $\left(\mathrm{F}_{(2,28)}=3.00, \mathrm{p}=0.07\right)$ or the HVA/ $\mathrm{DA}$ ratio $\left(\mathrm{F}_{(2,28)}=1.6 ; \mathrm{p}=0.22\right)$.

Neither in the hippocampus (HIP) nor in the prefrontal cortex (PFC) were there any significant differences in the levels of dopamine (HIP: $\mathrm{F}_{(2,28)}=1.77 ; \mathrm{p}=0.19 ;$ PFC: $\mathrm{F}_{(2,28)}=0.86$; $\mathrm{p}=0.44)$, the metabolites - DOPAC (HIP: $\mathrm{F}_{(2,28)}=1.45 ; \mathrm{p}=0.25$; PFC: $\left.\mathrm{F}_{(2.28)}=1.1 ; \mathrm{p}=0.34\right)$ and HVA (HIP: $\stackrel{(2,28)}{\mathrm{F}}_{(2,28)}=1.7 ; \mathrm{p}=0.2$; PFC: $\mathrm{F}_{(2.28)}^{(2.28)}=1.2 ; \mathrm{p}=0.32$ ), as well as DOPAC/DA (HIP: $\mathrm{F}_{(2,28)}=1.58 ; \mathrm{p}=0.22 ;$ PFC: $\left.\mathrm{F}_{(2,28)}=0.63 ; \mathrm{p}=0.54\right)$ and HVA/DA (HIP: $\mathrm{F}_{(2,28)}=0.12 ; \mathrm{p}=0.88$; PFC: $\left.\mathrm{F}_{(2,28)}=0.86 ; \mathrm{p}=0.43\right)$ ratio values.

5-hydroxytryptamine and metabolites. There was an increase in the 5 -HT content in the prefrontal cortex $\left(\mathrm{F}_{(2,28)}=3.37 ; \mathrm{p}=0.048\right)$, striatum $\left(\mathrm{F}_{(2,28)}=4.88 ; \mathrm{p}=0.0015\right)$ and spinal cord $\left(\mathrm{F}_{(2,28)}=14.64 ; \mathrm{p}=0.000044\right)$ in the DHE-treated groups. Differences in the concentration of 5-HIAA were noted in the prefrontal cortex $\left(\mathrm{F}_{(2,28)}=9.40 ; \mathrm{p}=0.00075\right)$ and medulla oblongata $\left(\mathrm{F}_{(2,28)}=6.58 ; \mathrm{p}=0.004\right)$. In rats that were given treatment, a decrease was observed in the levels of 5 -HIAA cortical concentration (DHE30 $=470.46 \pm 23.02 \mathrm{ng} / \mathrm{g}$; DHE100 $=379.83 \pm 21.547 \mathrm{ng} / \mathrm{g})$, compared to the control group (Con $=509.01 \pm 18.66 \mathrm{ng} / \mathrm{g})$.

In the medulla oblongata, the lowest 5-HIAA concentration was observed in the DHE100 group $(405.32 \pm 10.54 \mathrm{ng} / \mathrm{g})$, which was significantly different from other groups of rats (Con: 456.94 $\pm 6.87 \mathrm{ng} / \mathrm{g}$; DHE30: $453.51 \pm 14.02 \mathrm{ng} / \mathrm{g}$ ).

Serotonin concentrations in the hippocampus $\left(\mathrm{F}_{(2,28)}=0.008\right.$; $\mathrm{p}=0.99)$, cerebellum $\left(\mathrm{F}_{(2,28)}=1.77 ; \mathrm{p}=0.20\right)$ and medulla oblongata $\left(\mathrm{F}_{(2,28)}=3.06 ; \mathrm{p}=0.06\right)$, were not significantly different between the studied groups. Furthermore, no significant differences in the level of 5-HIAA in the hippocampus $\left(\mathrm{F}_{(2,28)}=1.14 ; \mathrm{p}=0.34\right)$, striatum $\left(\mathrm{F}_{(2,28)}=1.04\right.$; $\mathrm{p}=0.37)$, cerebellum $\left(\mathrm{F}_{(2,28)}=2.78 ; \mathrm{p}=0.079\right)$ and the spinal cord $\left(\mathrm{F}_{(2,28)}=1.82 ; \mathrm{p}=0.18\right)$ were registered.
The 5-HIAA/5-HT ratio was different among groups in the prefrontal cortex $\left(\mathrm{F}_{(2,28)}=37.85 ; \mathrm{p}=0.000000011\right)$, striatum $\left(\mathrm{F}_{(2,28)}=6.9 ; \mathrm{p}=0.0036\right)$, cerebellum $\left(\mathrm{F}_{(2,28)}=13.35 ; \mathrm{p}=0.000085\right)$, medulla oblongata $\left(\mathrm{F}_{(2,28)}=15.74 ; \mathrm{p}=0.00003\right)$ and the spinal cord $\left(\mathrm{F}_{(2,28)}=34.12 ; \mathrm{p}=0.000000031\right)$ (Fig. 4). In all brain regions, metabolite turnover was highest in the control group of rats, compared to treated animals. There were no differences in the 5-HIAA/5-HT ratio in the hippocampus $\left(\mathrm{F}_{(2,28)}=2.43 ; \mathrm{p}=0.11\right)$.

\section{DISCUSSION}

The mechanism of action of dihydroergotamine suggests that it may cause some neurotransmission and changes in behaviour, but no research on adult rodents focused on the behavioural consequences of long-term DHE administration has been described to-date. In the water maze test in the current study, it was noticed that long-term administration of dihydroergotamine to adult male rats was related to a higher swimming speed in the animals, both in the spatial and in the non-spatial version of the behavioural trials. An increase in the swimming velocity was observed during the learning phase (days 1-4, Fig.1A), both memory probe trials (days 5 and 10, Fig.1B and 1E), repeated training (day 8, Fig.1C), reversal training (day 9, Fig.1D) and visible platform examination (Fig. 1F). Swimming speed in the water maze may be affected by non-cognitive factors, such as motivation (escape from water) and locomotor abilities (swimming skills) of the rat [27]. The trial using a cued target in the water maze test was performed to determine if the substance examined in the study resulted in gross alterations of visual acuity that might confound the interpretation of data that depend on the use of proximal or distal visual cues. This test also allows for the estimation of motor and motivational aspects of animal behaviour [28]. Since both the mean path and escape latency to the visible platform were similar in all animals, it is believed that their visual and also basic motor abilities were intact. Regardless of the above, the DHE-administered animals were not motorically and/or motivationally equivalent with the controls, and showed an increased activity expressed by a higher velocity in swimming.

As the swimming speed of the rats was affected during the visible platform test, it may be assumed that in the present experiment motor effects were sufficient to influence the performance of the non-cued spatial water maze tasks. Despite the fact that higher speed of swimming of animals could contribute to the decreased values of mean escape latency to the platform, DHE-administered rats actually did not present the differences in cognitive ability when compared to controls. The phase of learning in the water maze (days 1-4) was the same in all animals, with similar values of mean escape latency. The results of probe trials, both on days 5 and 10 of the study showed no statistically significant differences in spatial memory in all tested groups of rats, regarding either the number of crossings over the position of the platform that had been previously placed in the SE/NW quadrants (Fig. 2A, Fig. 3A), or time spent in the particular sectors of the maze (Fig. 2B, Fig. 3B). Nevertheless, in the second memory test a tendency was noticed to improve memory with medium size effect (Cohen d >0.5) in DHE100 rats in terms of the number of crossings made over to the 
former platform position, as well as with small size effect (Cohen $\mathrm{d}<0.5$ ) over the new one.

In the vertebrate brain, monoamines mediate a variety of CNS functions as cognition, memory processing and motor control $[16,29]$. In the biochemical analysis in the current study, the changes were investigated in the level of monoamines and their metabolites in the selected areas of the brain responsible for these functions. Key structures for the initiation and execution of locomotion comprise the supraspinal controlling networks, i.e. mesencephalic locomotor region (MLR) that plays a prominent role in the modulation of the speed of locomotor movements, and receives an input from motor cortex, diencephalic, limbic and basal ganglia, as well basic controlling networks located in the spinal cord (central pattern generator - CPG) $[30,31]$.

In the current study, some changes were observed in the level of monoamines and their metabolites - generally a dosedependent increase in the concentration of monoamines in the prefrontal cortex, striatum, medulla oblongata and spinal cord, whereas in the hippocampus, monoaminergic transmission was not affected (Tab. 1).

The prefrontal cortex (PFC) contributes to motor control in rodents. Several research data have described the elevated content of dopamine [32,33], serotonin [34] and noradrenaline [35] in the PFC of hyperlocomotive methamphetaminetreated rats. The current study has demonstrated a dosedependent increase in the levels of prefrontal serotonin and noradrenaline (significant in DHE100 rats), while the dopamine content was not affected. The concentration of 5-HIAA (5-HT metabolite) decreased, whereas the MHPG level remained unchanged. It is possible that potentiated serotonergic and noradrenergic transmission in the PFC of DHE-treated rats may add to their increased locomotor activity observed in the water maze.

The mesolimbic dopamine system plays an important role in motivated behaviours, such as locomotion or learning, and is regarded as a component of the motor and reward systems [16,36]. Dopaminergic neurons innervate striatum and increase the exploratory behaviour of rodents, whereas the other monoamines - serotonin and noradrenaline - have a more complicated influence on the subcortical locomotioncontrolling systems. This effect is described as non-linear and dependent on secondary effects on other neurotransmitter systems, e.g. the dopaminergic system $[37,38]$. In the current study, the striatal dopamine level increased along with a dose of the DHE used (and was statistically relevant in DHE100 rats), while elevated content of serotonin was visible in all DHE-treated rats. Noradrenaline content was not affected, whereas the MHPG level was attenuated. These results are consistent with other studies linking hyperlocomotion and behavioural motivation with increased striatal dopaminergic activity $[29,39]$. They may also support the tendency to improve memory observed on day 10 in the water maze test.

In the hippocampus, the main structure involved in memory processes [29], no differences were observed in the biochemical analysis in the level of monoaminergic neurotransmitters between the groups of animals. Hippocampal monoamines, in general, support spatial learning processes [16]. Wang et al. [40] showed that the extracellular concentration of dopamine in the hippocampus is increased during spatial learning processes, and activates $\mathrm{D}_{1}$ receptors. It has also been reported that noradrenergic and dopaminergic signaling play a role in the novelty-related modulation of hippocampal memory [41, 42]. Increased serotonin content in the hippocampus usually improves spatial memory tasks; however, taking into account the complex response of 5-HT hippocampal receptors, research so far has produced inconsistent results [43]. Lack of differences in monoamine content in the hippocampus of DHE-treated rats versus controls may be compatible with small changes in the learning and spatial memory processes of the rats evaluated in the water maze in the presented study.

The mesencephalic locomotor region relays the motor responses via lateral paragigantocellular nucleus in the medulla oblongata to effector circuits in the spinal cord [44]. To the neurotransmitters in descending pathways that influence the spinal locomotor CPG belong, inter alia, serotonin, noradrenaline and dopamine [45]. In the current study, increased dopaminergic activity in the DHE-administered rats was noticed, both in the medulla oblongata and in the spinal cord, but serotonergic and noradrenergic transmission was enhanced only in the latter (Tab. 1). Dysregulation of monoaminergic neurotransmission in the spinal cord is able to affect locomotor functions. Catecholamines promote the activity of the networks that generate locomotion, and the spinal serotonergic system contributes both to induce and modulate locomotor behaviour [46]. Noradrenaline released by sympathetic nerve fibres and noradrenergic nuclei support the activation and control of spinal motor output. Swann et al. [47] demonstrated that the administration of quipazine, a serotonin receptor agonist, improved movement and body posture in independently moving newborn rat. Sławińska et al. [48] also showed that the administration of serotonin receptor agonists increases the agility of the hind limbs in rats with paraplegia of the hind limbs. It was thought that serotonergic neurons located in the spinal cord could initiate locomotor activity. The activation of serotonergic receptors can restore locomotor movement after damage to the spinal cord [49]. In view of such findings, the authors of this study suspect that the activation of spinal monoaminergic neurotransmission by DHE encourages the increased motor activity of animals, as observed in the study.

A generally decreased catabolic rate of monoamines, especially in the case of serotonin (Tab. 2, Fig. 4) was observed in the presented study. As the contents of metabolites were usually decreased (or unchanged) and the content of monoamines increased (or unchanged, the lowered DOPAC/DA, HVA/DA and 5-HIAA/5-HT ratios might reflect attenuated activity of monoaminooxidases (MAO) that contribute to the metabolism of monoamines [50]. Villégier et al. [51] showed a locomotor response in rodents treated with MAO inhibitors. This suggest that a stimulating impact of DHE on monoaminergic transmission via monoaminooxidase inhibition is possible.

\section{CONCLUSION}

The aim of this study was to provide a behavioural and biochemical analysis of the effects of long-term oral administration of dihydroergotamine in adult rats. The findings indicate that DHE administration has an impact on locomotor activity of the animals, perhaps by stimulating monoaminergic neurotransmission in the areas of the CNS related to locomotion control, especially in the striatum and in 
the spinal cord. Furthermore, DHE treatment may be linked with the tendency to improve the cognitive performance of the rats in the water maze. The results obtained provide a better insight into the consequences of long-term usage of dihydroergotamine in rodents.

\section{REFERENCES}

1. Baltic Sea Pharmaceuticals in the aquatic environment of the Baltic Sea region. A status report. Baltic Sea Environment Proceedings No. 149. The United Nations Educational, Scientific and Cultural Organization 7, place de Fontenoy, 75352 Paris 07 SP, France and HELCOM. UNESCO 2017. http://www.helcom.fi/Lists/Publications/BSEP149.pdf

2. Hanoun N, Saurini F, Lanfumey L, Hamon M, Bourgoin S. Dihydroergotamine and its metabolite, 8'-hydroxy-dihydroergotamine, as 5-HT1A receptor agonists in the rat brain. Br J Pharmacol. 2003; 139(2): 424-434. https://doi.org/10.1038/sj.bjp.0705258.

3. Bigal ME, Tepper SJ. Ergotamine and dihydroergotamine: a review. Curr. Pain Headache Rep. 2003; 7(1): 55-62. https://doi.org/10.1007/ s11916-003-0011-7.

4. González-Hernández A, Lozano-Cuenca J, Marichal-Cancino BA, Maassen Van Den Brink A, Villalón CM. Dihydroergotamine inhibits the vasodepressor sensory CGRPergic outflow by prejunctional activation of $\alpha 2$-adrenoceptors and 5-HT1 receptors. J Headache Pain. 2018; 19(1): 40. https://doi.org/10.1186/s10194-018-0869-8.

5. Deliganis AV, Peroutka SJ. 5-Hydroxtryptamine1D receptor agonism predicts antimigraine efficacy. Headache. 1991; 31(4): 228-231. https:// doi.org/10.1111/j.1526-4610.1991.hed3104228.x

6. Harriott AM, Strother LC, Vila-Pueyo M, Holland PR. Animal models of migraine and experimental techniques used to examine trigeminal sensory processing. J Headache Pain. 2019; 20(1): 91. https://doi. org/10.1186/s10194-019-1043-7.

7. Masterson CG, Durham PL. DHE repression of ATP-mediated sensitization of trigeminal ganglion neurons. Headache. 2010; 50(9): 1424-1439. https://doi.org/10.1111/j.1526-4610.2010.01714.x.

8. American Headache Society. The American Headache Society Position Statement On Integrating New Migraine Treatments Into Clinical Practice. Headache. 2019; 59(1): 1-18. https://doi.org/10.1111/ head.13456.

9. Piechal A, Blecharz-Klin K, Mirowska-Guzel D. Dihydroergotamine (DHE) - Is there a place for its use? J Pre-Clin Clin Res. 2018; 12(4): 149-157. https://doi.org/10.26444/jpccr/99878

10. Silberstein SD, Shrewbury SB, Hoekman J. Dihydroergotamine (DHE) - then and now: a narrative review. Headache, 2019. https:// doi.org/10.1111/head.13700

11. Saper JR, Silberstein S, Dodick D, Rapoport A. DHE in the pharmacotherapy of migraine: potential for a larger role. Headache. 2006; 46 (Suppl 4): S212-S220. https://doi.org/10.1111/j.15264610.2006.00605.x.

12. European Medicine Agency. CHMP referral assessment report: Ergot derivatives containing medicinal products. 2013, EMA/750626/2013. https:/www.ema.europa.eu/en/documents/referral/assessment-reportergot-derivatives-containing-medicinal-products-dihydroergotamine en.pdf. Accessed April 12, 2019.

13. Fioravanti M, Flicker L. Efficacy of nicergoline in dementia and other age associated forms of cognitive impairment. Cochrane Database Syst Rev. 2001; 4: CD003159. https://doi.org/10.1002/14651858.CD003159

14. Saletu B, Garg A, Shoeb A. Safety of nicergoline as an agent for management of cognitive function disorders. Biomed Res Int. 2014; 2014: 610103. http://dx.doi.org/10.1155/2014/610103.

15. Fioravanti M, Nakashima T, Xu J, Garg A. A systematic review and meta-analysis assessing adverse event profile and tolerability of nicergoline. BMJ Open. 2014; 4(7): e005090 (2014). http://dx.doi. org/10.1136/bmjopen-2014-005090.

16. Feldman RS, Meyer JS, Quenzer LF. Neurotransmitter systems. In: Principles of Neuropsychopharmacology, Sinauer Associates, Inc., Publishers, Sunderland, Massachusetts; 1997. pp. 277-390.

17. Saper JR, Silberstein SD. Pharmacology of dihydroergotamine and evidence for efficacy and safety in migraine. Headache. 2006; 46(Suppl.4): S171-S181. DOI: 10.1111/j.1526-4610.2006.00601.x.

18. Ala-Hurula V, Myllyla VV, Arvela P, Kärki NT, Hokkanen E. Systemic availability of ergotamine tartrate after three successive doses and during continuous medication. Eur. J Clin Pharmacol. 1979; 16(5): 355-60. https://doi.org/10.1007/BF00605636.
19. Goadsby PJ, Gundlach AL. Localization of 3H-dihydroergotaminebinding sites in the cat central nervous system: relevance to migraine. Ann Neurol. 1991; 29(1): 91-4. https://doi.org/10.1002/ana.410290116.

20. Pradalier A, Lantéri-Minet M, Géraud G, Allain H, Lucas C, Delgado A The PROMISE study: PROphylaxis of MIgraine with SEglor (dihydroergotamine mesilate) in French primary care. CNS Drugs. 2004; 18(15): 1149-63. https://doi.org/10.2165/00023210-200418150-00009.

21. Schürks M. Dihydroergotamine: role in the treatment of migraine. Expert Opin Drug Metab Toxicol. 2009; 5(9): 1141-8. https://doi. org/10.1517/17425250903164211.

22. Kayser V, Aubel B, Hamon M, Bourgoin S. The antimigraine 5-HT1B/1D receptor agonists, sumatriptan,zolmitriptan and dihydroergotamine, attenuate pain-related behaviour in a rat model of trigeminal neuropathic pain. Br J Pharmacol. 2002; 137, 1287-97. https://doi. org/10.1038/sj.bjp.0704979

23. Blecharz-Klin K, Piechal A, Jawna-Zboińska K, Pyrzanowska J, Wawer A, Joniec-Maciejak I, Widy-Tyszkiewicz E. Paracetamol - Effect of early exposure on neurotransmission, spatial memory and motor performance in rats. Behav Brain Res. 2017 Apr 14;323:162-171. https:// doi.org/ 10.1016/j.bbr.2017.01.051

24. Widy-Tyszkiewicz E, Scheel-Krüger J, Christensen AV. Enhanced disruptive spatial learning effect after sufentanil in renal hypertensive rats versus normotensive rats. Physiol Behav. 1993 Mar;53(3):467-75. https://doi.org/10.1016/0031-9384(93)90140-B

25. Pyrzanowska J, Piechal A, Blecharz-Klin K, Joniec-Maciejak I, Graikou K, Chinou I, Widy-Tyszkiewicz E. Long-term administration of Greek Royal Jelly improves spatial memory and influences the concentration of brain neurotransmitters in naturally aged Wistar male rats. J Ethnopharmacol. 2014; 155(1): 343-351. https://doi.org/10.1016/j. jep.2014.05.032.

26. Reed MN, Liu P, Kotilinek LA, Ashe KH. Effect size of reference memory deficits in the Morris water maze in Tg2576 mice. Behav Brain Res. 2010; 212(1): 115-20. https://doi.org/10.1016/j.bbr.2010.03.037.

27. Vorhees CV, Williams MT. Morris water maze: procedures for assessing spatial and related forms of learning and memory. Nat Protoc. 2006; 1(2): 848-58. https://doi.org/10.1038/nprot.2006.116

28. Vorhees CV, Williams MT. Assessing spatial learning and memory in rodents. ILAR Journal. 2014; 55(2): 310-332. https://doi.org/10.1093/ ilar/ilu013.

29. Kandel ER, Schwartz JH, Jessell TM, Siegelbaum SA, Hudspeth AJ. Principles of Neural Science. 5th ed. New York, NY: McGraw-Hill Medical; 2013.

30. Jordan L, Sławińska U. Chapter 17 - The Brain and Spinal Cord Networks Controlling Locomotion. In: Neuronal Networks in Brain Function, CNS Disorders, and Therapeutics, eds. Faingold CL, Blumenfeld H. Academic Press; 2014. pp. 215-233.

31. Gatto G, Goulding M. Locomotion Control: Brainstem Circuits Satisfy the Need for Speed. Curr Biol. 2018; 28(6): R256-R259. https://doi. org/10.1016/j.cub.2018.01.068.

32. Hall DA, Powers JP, Gulley JM. Blockade of D1 dopamine receptors in the medial prefrontal cortex attenuates amphetamine- and methamphetamine-induced locomotor activity in the rat. Brain Res. 2009; 1300: 51-57. https://doi.org/10.1016/j.brainres.2009.08.084

33. Ago Y, Tanaka T, Kita Y, Tokumoto H, Takuma K, Matsuda T. Lithium attenuates methamphetamine-induced hyperlocomotion and behavioral sensitization via modulation of prefrontal monoamine release. Neuropharmacol. 2012; 62(4): 1634-1639. https://doi. $\operatorname{org} / 10.1016 /$ j.neuropharm.2011.10.004.

34. Ago Y, Nakamura S, Kajita N, Uda M, Hashimoto H, Baba A, Matsuda T. Ritanserin reverses repeated methamphetamine-induced behavioral and neurochemical sensitization in mice. Synapse. 2007; 61(9): 757-63. https://doi.org/10.1002/syn.20421.

35. Drouin C, Blanc G, Villégier AS, Glowinski J, Tassin J. Critical role of alpha1-adrenergic receptors in acute and sensitized locomotor effects of D-amphetamine, cocaine, and GBR 12783: influence of preexposure conditions and pharmacological characteristics. Synapse. 2002; 43(1): 51-61. https://doi.org/10.1002/syn.10023.

36. Alcaro A, Huber R, Panksepp J. Behavioral functions of the mesolimbic dopaminergic system: an affective neuroethological perspective. Brain Res Rev. 2007; 56(2): 283-321. https://doi.org/10.1016/j. brainresrev.2007.07.014.

37. Viggiano D. The hyperactive syndrome: Metanalysis of genetic alterations, pharmacological treatments and brain lesions which increase locomotor activity. Behav Brain Res. 2008; 194(1): 1-14. https:// doi.org/10.1016/j.bbr.2008.06.033.

38. Ikeda H, Kamei J, Koshikawa N, Cools AR. Nucleus accumbens and dopamine-mediated turning behavior of the rat: role of accumbal 
non-dopaminergic receptors. J Pharmacol Sci. 2012; 120(3): 152-164. https://doi.org/10.1254/jphs.12R02CR.

39. Arias-Carrión O, Stamelou M, Murillo-Rodríguez E, MenéndezGonzález M, Pöppel E. Dopaminergic reward system: a short integrative review. Int Arch Med. 2010; 3: 24. https://doi.org/ 10.1186/1755-7682$3-24$.

40. Wang F, Wan P, Wang W, Xiao B, Jin H, Jin Q. Dopamine in the hippocampal dentate gyrus modulates spatial learning via D1-like receptors. Brain Res Bull. 2019; 144: 101-107. https://doi.org/10.1016/j. brainresbull.2018.11.010.

41. McNamara CG, Dupret D. Two sources of dopamine for the hippocampus. Trends Neurosci. 2017; 40(7): 383-384. https://doi. org/10.1016/j.tins.2017.05.005.

42. Moreno-Castilla P, Pérez-Ortega R, Violante-Soria V, Balderas I, Bermúdez-Rattoni F. Hippocampal release of dopamine and norepinephrine encodes novel contextual information. Hippocampus. 2017; 27(5): 547-557. https://doi.org/10.1002/hipo.22711.

43. Dale E, Pehrson AL, Jeyarajah T, Li Y, Leiser SC, Smagin G, Olsen CK, Sanchez C. Effects of serotonin in the hippocampus: how SSRIs and multimodal antidepressants might regulate pyramidal cell function. CNS Spectr. 2015; 21(2): 143-61. https://doi.org/10.1017/ S1092852915000425.

44. Gatto G. and M. Goulding, 2018. Locomotion Control: Brainstem Circuits Satisfy the Need for Speed. Curr Biol. 2018; 28(6): R256-R259. https://doi.org/10.1016/j.cub.2018.01.068.
45. Jordan L, Sławińska U. Chapter 17 - The Brain and Spinal Cord Networks Controlling Locomotion. In: Neuronal Networks in Brain Function, CNS Disorders, and Therapeutics, eds. Faingold CL, Blumenfeld H. Academic Press; 2014. pp: 215-233.

46. Sharples SA, Koblinger K, Humphreys JM, Whelan PJ. Dopamine: a parallel pathway for the modulation of spinal locomotor networks. Front. Neural Circuits. 2014; 8: 55. https://doi.org/10.3389/fncir.2014.00055.

47. Swann HE, Kempe RB, Van Orden AM, Brumley MR. Serotonergic activation of locomotor behavior and posture in one-day old rats. Behav Brain Res. 2016; 302: 104-14. https://doi.org/10.1016/j.bbr.2016.01.006.

48. Sławińska U, Majczyński H, Dai Y, Jordan LM. The upright posture improves plantar stepping and alters responses to serotonergic drugs in spinal rats. J Physiol. (Lond.) 2012; 590(7): 1721-1736. https://doi. org/10.1113/jphysiol.2011.224931.

49. Sławińska U, Miazga K, Jordan LM. The role of serotonin in the control of locomotor movements and strategies for restoring locomotion after spinal cord injury. Acta Neurobiol Exp. (Wars) 2014; 74(2): 172-87. PMID: 24993627.

50. Bortolato M, Chen K, Shih JC. Monoamine oxidase inactivation: from pathophysiology to therapeutics. Adv Drug Deliv Rev. 2008; 60(13-14): 1527-33. https://doi.org/10.1016/j.addr.2008.06.002.

51. Villégier AS, Salomon L, Granon S, Changeux JP, Belluzzi JD, Leslie FM, Tassin JP. Monoamine oxidase inhibitors allow locomotor and rewarding responses to nicotine. Neuropsychopharmacology. 2006; 31(8): 1704-13. https://doi.org/10.1038/sj.npp.1300987. 